\title{
How severe space weather can disrupt global supply chains
}

\author{
H. Schulte in den Bäumen ${ }^{1}$, D. Moran ${ }^{2}$, M. Lenzen ${ }^{1}$, I. Cairns ${ }^{1}$, and A. Steenge \\ ${ }^{1}$ School of Physics A28, University of Sydney, Sydney NSW 2006, Australia \\ ${ }^{2}$ Programme for Industrial Ecology, Norwegian University of Science and Technology (NTNU), 7013 Trondheim, Norway \\ ${ }^{3}$ The University of Groningen, Faculty of Economics and Business, 9700 AB Groningen, the Netherlands
}

Correspondence to: H. Schulte in den Bäumen (hagen@ physics.usyd.edu.au)

Received: 5 June 2014 - Published in Nat. Hazards Earth Syst. Sci. Discuss.: 24 June 2014

Revised: - - Accepted: 4 September 2014 - Published: 10 October 2014

\begin{abstract}
Coronal mass ejections (CMEs) strong enough to create electromagnetic effects at latitudes below the auroral oval are frequent events that could soon have substantial impacts on electrical grids. Modern society's heavy reliance on these domestic and international networks increases our susceptibility to such a severe space-weather event. Using a new high-resolution model of the global economy, we simulate the economic impact of strong CMEs for three different planetary orientations. We account for the economic impacts within the countries directly affected, as well as the post-disaster economic shock in partner economies linked by international trade. For a 1989 Quebec-like event, the global economic impacts would range from USD 2.4 to 3.4 trillion over a year. Of this total economic shock, about $50 \%$ would be felt in countries outside the zone of direct impact, leading to a loss in global Gross Domestic Product (GDP) of 3.9 to $5.6 \%$. The global economic damage is of the same order as wars, extreme financial crisis and estimated for future climate change.
\end{abstract}

\section{Introduction}

Solar storms consist of three major components: solar flares, solar proton events and coronal mass ejections (CMEs). All of these cause "space weather" that affect humanity's technological systems and society, as well as Earth's atmosphere, climate, and potentially the biosphere. Fast CMEs $(\approx 1000$ $2000 \mathrm{~km} \mathrm{~s}^{-1}$ ) are clouds of ejected plasma with embedded magnetic fields that can interact with Earth's magnetic field after an observed travel time as short as $15 \mathrm{~h}$ to create a geomagnetic storm (Cliver and Svalgaard, 2004). Following this impact, Earth's magnetic field can be disturbed worldwide for days (Bolduc, 2002), allowing more energetic solar and magnetospheric charged particles to find their way along the open magnetic field lines near the Earth's poles through the ionosphere and atmosphere to the surface. Many details of the associated physics are still unclear. However, currents and electric fields associated with enhanced particle precipitation can induce massive ground currents in electrical distribution networks which could result in large-scale power blackouts and permanent damage to electric transformers (Pirjola et al., 2000).

The strength of the induced currents depends on a number of factors. They usually increase with geomagnetic latitude, transmission line length and voltage, but decrease with distance to the ocean and increased ground resistivity (Wei et al., 2013). Space-weather events also cause auroras, usually in two small ovals around $65( \pm 5)$ degrees northern and southern latitude that vary in size, location and intensity during geomagnetic storms. The geographical distribution of the damage caused by a geomagnetic storm is very complex. Other observed consequences of geomagnetically induced currents (GICs) include damage to pipelines and telecommunication cables, accelerated corrosion, physical and electrical damage to satellites, and disruptions to radio navigation, which can particularly affect the transport and aviation sectors (Royal Academy of Engeeniering, 2013).

In 1989, Earth experienced its largest space-weather event in several decades: a geomagnetic storm that caused a power blackout in Quebec that left millions of people without electricity for hours. It permanently damaged transformers in Canada, the USA and the UK, and disconnected other power transmission devices from California to Sweden (Erinmez, 2002; Lakhina et al., 2005). This storm caused damage across about $120^{\circ}$ of longitude and $5-10^{\circ}$ latitude, and lasted for 
more than $12 \mathrm{~h}$. The Quebec power grid went from normal operations to complete shutdown in $90 \mathrm{~s}$. Temporal changes in the geomagnetic field of $\mathrm{d} B / \mathrm{d} t=1100 \mathrm{nT} \min ^{-1}$ were experienced and the strength of the storm, in terms of the disturbance storm index, which measures how much Earth's magnetic field is weakened, was estimated to be $D_{\mathrm{st}}=-640 \mathrm{nT}$. Two other strong storms in the 20th century include a $\mathrm{d} B / \mathrm{d} t=5000 \mathrm{nT} \min ^{-1}$ storm in May 1921, the biggest geomagnetic event in the last century. It lead to aurora borealis over Samoa, and a fast CME in October 2003 which, despite its low strength of $D_{\mathrm{st}}=-472 \mathrm{nT}$, caused effects at latitudes as low as South Africa, where it incapacitated several large electrical transformers (Lakhina et al., 2005). Regions with latitudes below $30^{\circ} \mathrm{S}$ were previously thought to stay free of damage.

Studies and anecdotal evidence suggest the most severe space-weather event in the last 450 years was the Carrington event of September 1859 (e.g., Cliver and Svalgaard, 2004). This storm caused auroras visible within $23^{\circ}$ of the equator in both hemispheres, e.g., in Honolulu, Havana, and Rome (Tsurutani et al., 2003). In the United States and Europe, fires were started by arcing from currents induced in telegraph wires (Green et al., 2006). The strength of this storm has been estimated to be $850 \mathrm{nT} \leq D_{\mathrm{st}} \leq-1760 \mathrm{nT}$ (Lakhina et al., 2005; Sicsoe et al., 2006; Tsurutani et al., 2012). In August 2013, a CME of Carrington size missed the Earth by a week, or $90^{\circ}$ in heliographic longitude.

Although a solar maximum period might have a higher frequency of intense solar storms, there is no evidence that this will affect the intensity of any single event (Hapgood, 2012). Indeed, the 1859 event occurred outside of solar maximum. The probability of a Carrington event (based on $\left.D_{\mathrm{st}}<850 \mathrm{nT}\right)$ per decade is estimated to be $12 \%$, or a once-in-a-century event like a 9.0 earthquake (Riley, 2012; Love, 2012). It has been estimated (Thomson et al., 2011) that $\mathrm{d} B / \mathrm{d} t$ changes of $1000-4000 \mathrm{nT} \mathrm{min}^{-1}\left(D_{\mathrm{st}}=2000\right.$ $5000 \mathrm{nT}$ ) for a storm occur every 100 years and $\mathrm{d} B / \mathrm{d} t$ of $1000-6000 \mathrm{nT} \mathrm{min}^{-1}\left(D_{\mathrm{st}}=3000-6500 \mathrm{nT}\right)$ every 200 years. These frequencies are comparable to other severe natural disasters, such as large earthquakes and volcanic eruptions. Power grids typically experience problems when the rate of change of the magnetic field exceeds a 100$200 \mathrm{nT} \mathrm{min}^{-1}$ (Wei et al., 2013). Occurring today, the Quebec 1989 event or the 1859 Carrington event would have a profound impact on the daily lives of millions of people, both through direct effects and via the impacts to the globalized economic production system.

Little has been done on economic modeling of severe space weather so far, and previous studies have mostly focused on the USA. It has been estimated in NAOS (2008) and Showstack (2011) that a storm similar to that of 1859 or 1921 could cause damage of several trillion US dollars in the USA in the first year alone, and that recovery could take years. The estimated damage to the power system in Quebec in 1989 is in the range of USD 2 billion, whilst the total dam- age is estimated to be around USD 13 billion (Kappenmann, 2010; Boteler, 1998). Another study estimates that the economic losses in North America and Europe for a power blackout for 5 months caused by a Carrington-like event would be between USD 0.5 and 2.6 trillion (Lloyd's, 2013; Wei et al., 2013). It has also been estimated that a North American power grid blackout would result in a GDP loss in the USA of about USD 30 billion per day, accumulating to over USD 10 trillion per year (Lloyd's, 2013). None of the cost estimates consider global effects due to international trade.

The complex and interconnected network of today's globalized economy and infrastructure makes it difficult to predict the exact effects of a severe space-weather event. Therefore, we focus on the most economically important impact from such an event: the interruption of electrical distribution grids and failure of electric power transmission systems. We combine a simple physical model for disruption of power grids with the most comprehensive and most highly resolved economic input-output framework of the world economy to estimate the direct and indirect economic costs of severe space-weather events of sizes between the Quebec 1989 and Carrington 1859 events.

The reduction of production capacities $\gamma_{\mathrm{el}}$ of the electricity sector for each country $C=1, \ldots, 187$ is dependent on the size $S$ and the location $\phi_{0}$ of the event. Specifically,

$$
\begin{aligned}
& \gamma_{\mathrm{el}}=F(S) A_{C}^{-1} \int \mathrm{d} A G\left(S, C, \phi_{0}\right) \\
& =F(S) A_{C}^{-1} \int \mathrm{d} A e^{\frac{-\left(\phi-\phi_{0}\right)^{2}}{2 \sigma_{\phi}(S)^{2}}} \times\left[e^{\frac{-\left(\theta-\theta_{0}(S)\right)^{2}}{2 \sigma_{\theta}(S)^{2}}}+e^{\frac{-\left(\theta+\theta_{0}(S)\right)^{2}}{2 \sigma_{\theta}(S)^{2}}}\right] .
\end{aligned}
$$

The quantity $G\left(S, C, \phi_{0}\right)$ is the product of a Gaussian in longitude $\phi$, centered at longitude $\phi_{0}$ (which corresponds to the time when the event occurred) with event-dependent standard deviation $\sigma_{\phi}(S)$, that depends on the event size $S$, times the sum of Gaussian distributions in latitude that model the event-dependent auroral ovals centered at $\pm \theta_{0}(S)$ with standard deviations $\sigma_{\theta}(S)$. Figure 1 illustrates the double-banded nature of the affected areas.

How should $\theta_{0}(S), \sigma_{\theta}(S)$ and $\sigma_{\phi}(S)$ vary with $S$ ? Noting that the magnetic field $B(r)$ at radial distance $r$ from a long axial current $I$ varies as $B(r)=\mu_{0} I / 2 \pi r$, where $\mu_{0}$ is the permittivity of free space, it is clear that the distance $r$, at which the same value of $B$ is observable, increases linearly with $I$. Thus, as a first approximation $\sigma_{\theta}(S)$ and $\sigma_{\phi}(S)$ should vary linearly with $I$, and also with $S$. Observations show that $\theta_{0}(S)$ decreases from values near to $65^{\circ}$ geographical latitude as $S$ increases, since the aurora moves equatorward as geomagnetic storms and the associated currents intensify and then move poleward as the driving currents decrease and the system recovers (Baumjohann et al., 1980). Thus, the geographical area in which a certain level of damage occurs should vary as $S^{2}$, but should move equatorward as $S$ increases. 


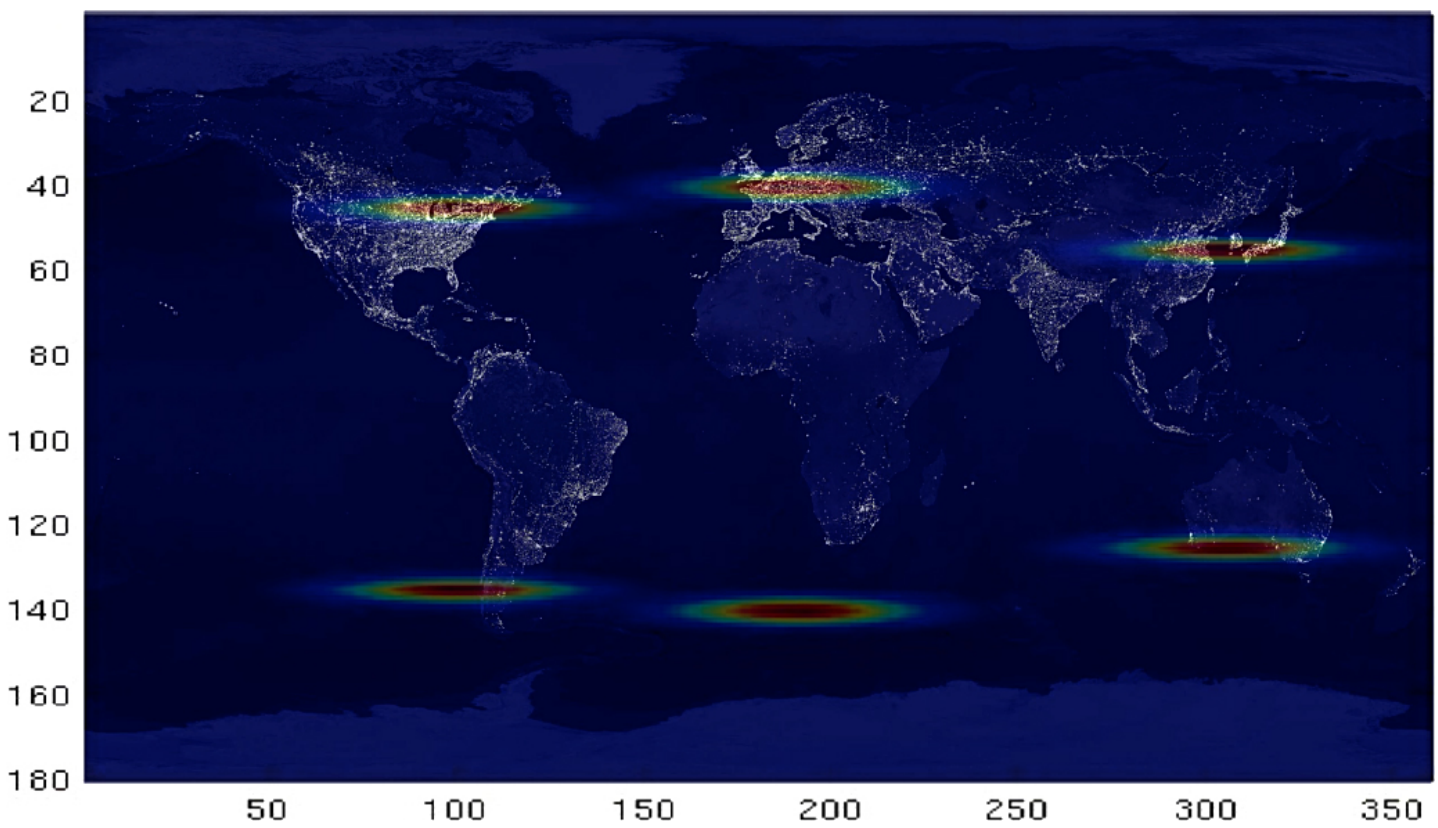

Figure 1. Earth at night with Quebec-like events over the Americas (scenario 1), Europe and the southern ocean (scenario 2), and East Asia and Australia (scenario 3). The red area has the highest storm intensity normalized to 1 . The storm's intensity has a Gaussian falloff.

We assume $\sigma_{\theta}=2 \pm 1^{\circ}$ and $\sigma_{\phi}=20 \pm 5^{\circ}$ for a storm similar to the Quebec 1989 space-weather event. This storm has a footprint of about $80^{\circ}$ of longitude and about $8^{\circ}$ of latitude in both the northern and southern hemisphere. Since the $D_{\text {st }}$ and AL values for the Quebec 1989 and Carrington 1859 events are believed to have differed by a factor of 3 , the geographical footprint of the Carrington event is expected to be a factor of 9 larger and the values of $\sigma_{\theta}$ and $\sigma_{\phi}$ each a factor of 3 larger. From the physical model, $\sigma_{\theta}=6 \pm 3^{\circ}$, and $\sigma_{\phi}=60 \pm 15^{\circ}$. During the Carrington event, auroras were observed as far south as $20^{\circ}$ latitude with the latitudinal spread observed to be $45^{\circ}$, and the longitudinal domain was close to $180^{\circ}$ (Green et al., 2006). Accordingly, the model is consistent with observations.

For each country, the total impact of the storm is the quantity $R$ that integrates the storm's effects as a function of geomagnetic latitude and longitude over the country's area. The storm is modeled like a flash-like impact. Outside the area of impact, the damage in the electricity sector is zero. Storms weaker than the Carrington 1859 event but stronger than the Quebec 1989 event could result in around 10-20 damaged transformers in the US alone (OECD, 2011; MITRE, 2011; UK House of Commence Defence Committee, 2012). Even the failure of a small number of transformers serving a highly populated area, like the ones we choose in our scenario, is enough to create prolonged power outage. We assume that the storm causes damage which will last a year since the production and supply of a replacement transformer could take up to more than 12 months, as could the restoration of a grid damaged over a huge area (OECD/IFP, 2012).
In order to quantify the economic impacts of a severe space-weather event, we simulate the consequences of major disasters by utilizing Leontief's input-output (IO) theory (Steenge and Boèkarjova, 2007; Leontief, 1966). IO analysis has been used extensively for investigating the repercussions of changes in one part of an economy on other parts of the same economy (see the recent articles by Lenzen et al., 2011; Wiedmann et al., 2013). IO databases are routinely published by more than 100 national statistical bureaus in the world. More recently, a number of teams have assembled large-scale, detailed global multi-regional input-output (MRIO) databases, which contain the same set of data but are integrated for all world regions or countries (Tukker and Dietzenbach, 2013). MRIO tables can be used in the same analytical manner as national IO tables, for investigating effects that ripple along global supply-chain networks (Leontief and Strout, 1963). In this study, we utilize the most detailed of these global MRIO database, distinguishing $M=187$ countries with 25-400 sectors per country (Lenzen et al., 2013). The economic model captures more than $99.99 \%$ of global trade.

\section{The model}

IO tables show transactions occurring within an economy: the flow of money and the counterflow of goods and services. The intermediate or inter-industry transaction matrix $\boldsymbol{T}$ contains transactions occurring between industries or sectors. For example, the manufacturing industry buys basic steel from the steel manufacturing industry, which, in 
turn, purchases iron ore from the mining sector. The purchasing sectors are listed horizontally along the columns, while the sectors running vertically down the rows are selling the goods and services. The transactions contained in $\boldsymbol{T}$ are termed intermediate because the purchases are products which are themselves used in the production of other products. The purchase of final products occurs in the final demand vector $\boldsymbol{y}$. These are products produced for the final consumer. A basic requirement of IO tables is that they balance out; the inputs to an economy must equal the outputs. The total output of the economy is equal to the output of industry plus the output to final consumers. To accomplish the addition of the corresponding matrices, a summation operator is used: $\boldsymbol{x}=\boldsymbol{T} 1+\boldsymbol{y}$, where $1=\{1,1, \ldots, 1\}$ ' is an $N \times 1$ summation operator.

Most often, productive activity in modern economies is assumed to be demand-driven, and the so-called demand-pull model is evoked, where an initial change vector $\Delta \boldsymbol{y}$ in final demand $\boldsymbol{y}(N \times 1$, for example, decreased household consumption caused by reduced electricity supply) causes flowon effects that ripple through a complex upstream supplychain network, and ultimately leads to a change $\Delta \boldsymbol{x}$ in total output $\boldsymbol{x}(N \times 1)$ of an economy. The scalar $N$ holds the number of sectors (industries and/or products) that are distinguished in the IO matrices. We distinguish $P=15909$ country-sector pairs (Lenzen et al., 2013, 2014) using data from 2011. The flow-on effects can be enumerated using an $N \times N$ IO transactions matrix, $\mathbf{T}$, according to $\Delta \boldsymbol{x}=$ $\left(\mathbf{I}-\mathbf{T} \hat{\boldsymbol{x}}^{-1}\right)^{-1} \Delta \boldsymbol{y}=(\mathbf{I}-\mathbf{A})^{-1} \Delta \boldsymbol{y}$, where $\mathbf{I}$ denotes an $N \times N$ identity matrix, the hat symbol " " denotes matrix diagonalization, and $\mathbf{A}=\mathbf{T} \hat{\boldsymbol{x}}^{-1}$ is the matrix of input coefficients. This relationship follows from the national accounting identity, which states that $\boldsymbol{x}=\mathbf{T} 1+\boldsymbol{y}=\mathbf{A} \boldsymbol{x}+\boldsymbol{y}$. A transaction matrix, $\mathbf{T}$, is essentially a square matrix with elements $T_{\mathrm{ij}}$ that represent the supply of products $i$ for use in industry $j$. Matrices $\mathbf{T}$ and $\mathbf{A}$ thus include information on industrial interdependence and production structures in an economy, which can ultimately be used to trace flow-on effects of initial changes along supply chains that link all sectors in a global economy.

Rather than following the effects of changes in final demand on levels of total output, we analyze a situation where the output of economies undergoes forced changes, and study the effects that these changes have on final demand or consumption possibilities. Such studies are generally known as disaster-impact analysis (Li et al., 2013; Okuyama, 2007). Our approach to estimating the direct and indirect consequences of a severe space-weather event affecting a specific set of countries $C=1, \ldots, M$ and industries $i=1, \ldots, N$ leads to an $N \times N$ diagonal matrix of fractions $\gamma$ of production capacity lost due to the event. The diaster-impact method and the derivation of the $\gamma$ matrix are described in detail in
Appendix A.

$\boldsymbol{\Gamma}(C, i)=\left[\begin{array}{lll}\gamma_{C=1, i=1} & & \\ & \ddots & \\ & & \gamma_{C=R, i=N}\end{array}\right]$,

with $0 \leq \gamma \leq 1$. $\Gamma$ not only has entries in the electricity sector(s), but also in the industrial sector(s) directly and indirectly affected by reduced electricity supply. In assuming that pre-disaster production is represented by total output $\boldsymbol{x}$, the post-disaster production possibilities are then $\tilde{\boldsymbol{x}}=(\mathbf{I}-\boldsymbol{\Gamma}) \boldsymbol{x}$. This formulation is equivalent to the model in Eqs. (17) and (21)-(23) in Steenge and Boèkarjova (2007). The result of a reduced industrial production $\tilde{\boldsymbol{x}}$ is a state of reduced postdisaster consumption, i.e., final demand $\tilde{\boldsymbol{y}}$. Since $\mathbf{A} \tilde{\boldsymbol{x}}+\boldsymbol{y} \neq \tilde{\boldsymbol{x}}$, the national accounting identity does not hold after the disaster, and the global economy is in imbalance. In particular, the reduced output is insufficient for satisfying final demand $\boldsymbol{y}$. Reduced post-disaster consumption possibilities are $\tilde{\boldsymbol{y}}=\tilde{\boldsymbol{x}}-\mathbf{A} \tilde{\boldsymbol{x}}$. Note that this formulation assumes that the production recipe $\mathbf{A}$ is constant, at least in the short term (within a year). This means that production processes in those industries affected cannot be altered (for example, by substituting electricity with other energy carriers) in order to make up for lost capacities.

In a case where final demand is unable to shoulder the entire loss in production possibilities, we examine the Leontief inverse or total requirement matrix $\mathbf{L}=(\mathbf{I}-\mathbf{A})^{-1} \cdot \mathbf{L}=\left[l_{\mathrm{ij}}\right]$ reveals how much gross output of each sector is required to meet final demand. We then see that the lost electricity supply is quite an important production input for some sectors, but a very small input for others. If electricity is a very small input (we define a threshold for small), we decide that this sector is not hit by the global cascade, e.g., because this sector can substitute the small input with some other commodity. For sectors in which electricity is a significant input ( $\mathbf{L}_{C, i}>$ threshold), we reduce the output of that sector as described above. The threshold is determined according to the global requirement of electricity supply from the electricity sectors directly damaged due to the geomagnetic storm (Fig. 2). In scenario 1, for example, 1328 different sectors require two times $10^{-5}$ the total supply from the damaged electricity sectors as a production input. If the total required production input of one of these sectors is typically USD 2 billion, and electricity supply from the damaged sectors is $2 \times 10^{-5}$ of it, USD 1000 worth of electricity are required as a production input. We argue that this sector can substitute USD 1000 worth of input of electricity with USD 1000 worth of, for example, wood. Our threshold for this scenario is $2 \times 10^{-5}$. 


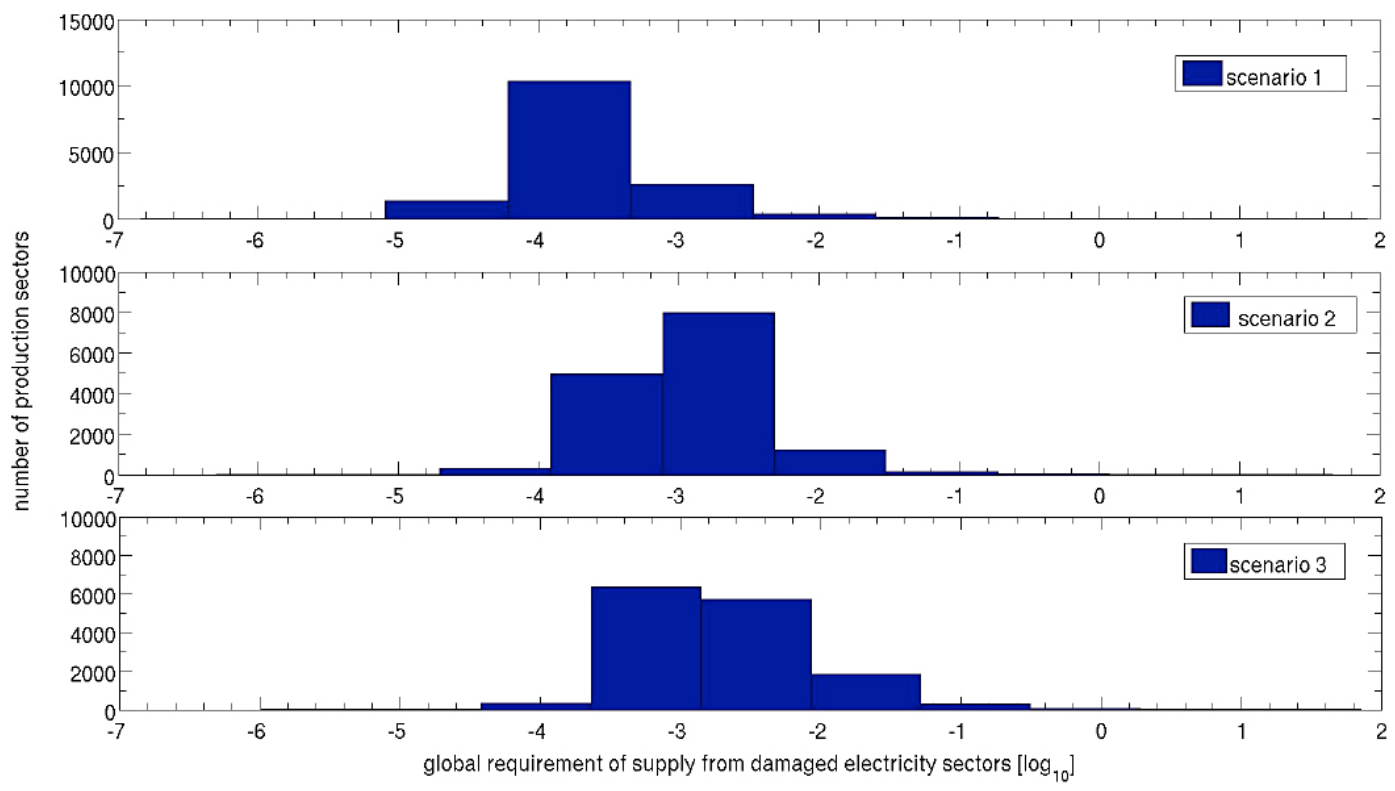

Figure 2. Global production requirement of supply from damaged electriciy sectors. The treshold for scenario 1 is $2 \times 10^{-5}$, for scenario 2 $5 \times 10^{-5}$, and for scenario $31 \times 10^{-6}$.

\section{Results}

A large number of calculations run in which the storm size $S$, the damage factor $F(S)$ - which describes the lost production capacity in the event-affected electricity sector(s) -, and the location $\phi_{0}$ of the storm were varied. Considering direct effects only, we simulated a complete grid shutdown in the USA, i.e., $F(S)=1$. This scenario leads to direct economic damage in the USA of about USD 25 billion per day, which is similar to the USD 30 billion per day impact estimated (Lloyd's, 2013). To simulate the economic damage of Quebec- and Carrington-like events, we use $F(S)=0.1$, meaning that, in areas of maximal storm intensity, $10 \%$ of the electricity supply is lost, in order to get similar damage as estimated in previous studies. Using this value for $F(S)$, while still considering direct effects only, a Quebeclike event occurring today centered over Quebec would cause daily economic damage in Canada of USD 165 million and USD 2.65 billion in the USA. This value is close to the estimates of USD 13 billion over 5 days for the event (Boteler et al., 1998). Similarly, a Carrington event occurring today centered near New York $\left(\phi_{0}=40^{\circ} \mathrm{N}, \theta_{0}=75^{\circ} \mathrm{W}\right)$ would lead to direct economic damage of about USD 1.2 trillion for 5 months in the USA alone. These results are in line with prior estimates of USD 0.5-2.6 trillion (Wei et al., 2013; Lloyd's, 2013). Note that all economic impact studies conducted to date do not consider indirect effects due to disrupted intra- and international trade.

We run the model, still with $F(S)=0.1$, but now considering direct and indirect effects, with Quebec-like scenarios for six different locations (Fig. 1): centered over Amer- ica at $\phi_{0}= \pm 45^{\circ} \mathrm{N}$ and $\theta_{0}=80^{\circ} \mathrm{W}$ (scenario 1), over Europe/Africa at $\phi_{0}= \pm 50^{\circ} \mathrm{N}$ and $\theta_{0}=10^{\circ} \mathrm{E}$ (scenario 2), and over Asia/Australia at $\phi_{0}= \pm 35^{\circ} \mathrm{N}$ and $\theta_{0}=125^{\circ} \mathrm{E}$ (scenario 3 ). These targets were chosen as economically worstcase scenarios since they affect densely populated and highly industrialized regions.

In all scenarios, we see economic damage not only in the countries directly affected by the storm, but also in partner countries affected by disruptions in international trade and supply chains (red shading in Figs. 3-5). This is because industries that rely on imports that, in turn, directly or indirectly depend on supplies from the damaged electricity sector(s), face input shortages, and hence have to scale back their production. However, we also find that some countries are faced with increases in consumption possibilities (green shading). This is because industries producing inputs that are directly or indirectly required by the damaged electricity sector(s) are not needed anymore since the electricity sector(s) operates at reduced capacity, and hence the output of the industries producing these inputs is available for additional domestic consumption. Whilst the latter situation provides in principle increased consumption possibilities, our model does not reveal whether adequate final demand will in fact be forthcoming to absorb the surplus production capacity. For the purpose of this study, we simply report on two types of economic imbalances, where (a) shortages of electricity inputs lead to production deficits and curtailed demand, and where (b) reduced demand for inputs by (an) electricity sector(s) leads to surplus production that may remain unused.

For scenario 1 centered over the Americas, we find (Fig. 3) that disruption of US power utilities would cause major 


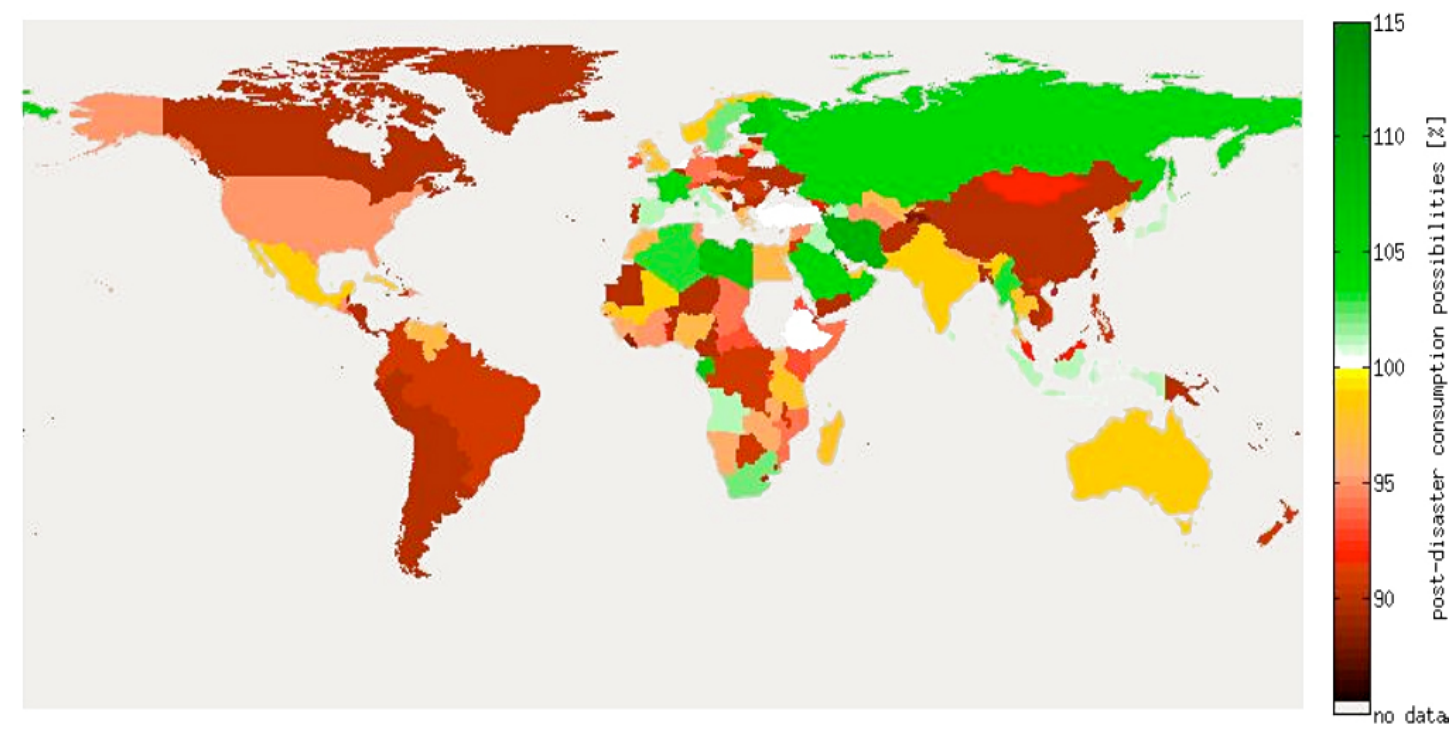

Figure 3. Effects of scenario 1, a Quebec 1989-like event centered over the Americas. Globally, the storm would reduce total consumption possibilities by $3.9 \%$ though the effect is uneven: it is most severe in countries directly affected and their economic partners, while other countries (e.g., Russia, Saudi Arabia, France, and Egypt) may gain consumption possibilities in the post-disaster economy.

losses in Canada (for example, due to reduction in US vehicle supply), Germany (reduction in supply of US pharmaceutical products, industrial machinery and precision equipment), and China (electrical equipment, aircraft, plastic products). Economic loss for Canada in relative terms is even larger than for the USA, even though the USA is far more severely affected directly by the storm, because of Canada's smaller economy and strong dependence on key US exports. Countries featuring surplus production are those that specialize in exporting key resources into the USA; for example, Russia (petroleum, aluminum, nickel, iron and chemicals), Saudi Arabia, Libya, Azerbaijan, Kazakhstan, and Algeria (oil), South Africa and Gabon (precious minerals), France and Sweden (aircraft parts, power generating equipment), and Finland (paper). An examination of the UN Main Aggregates database (UNSD, 2011) shows that almost all of the countries characterized by increased consumption possibilities feature a consistent and significant trade surplus (Qatar, Libya, Gabon, Kuwait, Saudi-Arabia, Oman, Algeria, Azerbaijan, Russia, Angola, Myanmar, Iran, Kazakhstan).

Scenario 2 looks markedly different (Fig. 4). It appears that the world's dependence on European exports of all kinds means that virtually all countries, except for the USA, are affected by GDP losses as a result of a severe space-weather events over Europe. The USA registers net-production surplus because of key exports to Europe, such as integrated circuits and other semiconductor products, pharmaceutical and chemical products, as well as vehicles and aircraft.

Scenario 3 (Fig. 5) shows that a space-weather event affecting China, Japan, Korea and Australia causes GDP loss across most of Europe. Libya, Iran and Azerbaijan are exceptions because of their significant oil exports. The role of the USA requires closer examination. For example, whilst China received net damage from a storm over the USA, the USA appeared to be affected by surplus production as a result of a storm over China, even though China's exports to the USA far outstrip US exports to China. This is because, whilst US exports to China (semiconductor components, soybeans, aircraft, and cars) are important inputs into further production, China's exports to the USA (digital disk drives, clothes, games, toys, furniture) are mostly destined for the final consumer, and hence have no damage-multiplying effect. Brazil is an equally interesting case here, because, whilst being a net importer from the USA and most of Europe, it is a net exporter to China, Japan, Korea, and Australia, and hence registers surplus production after a storm.

The economic model considers both direct impacts in international trade, such as the shared international power grids in Europe, and the indirect effects due to interrupted supply chains. In scenario 1, an American storm, indirect plus direct effects are calculated to reduce global consumption possibilities by $3.9 \%$ or USD 2.4 trillion. In scenario 2 (the European storm), direct and indirect effects are calculated to reduce global consumption possibilities by $5.6 \%$ or USD 3.4 trillion. In the Asia-centered storm of scenario 3, the storm is estimated to reduce global consumption possibilities by $5.0 \%$, or USD 3.1 trillion.

\section{Discussion}

In this paper, we concentrated on the possible impact of severe space-weather events on the electric distribution system. A space-weather event is substantially different from other 


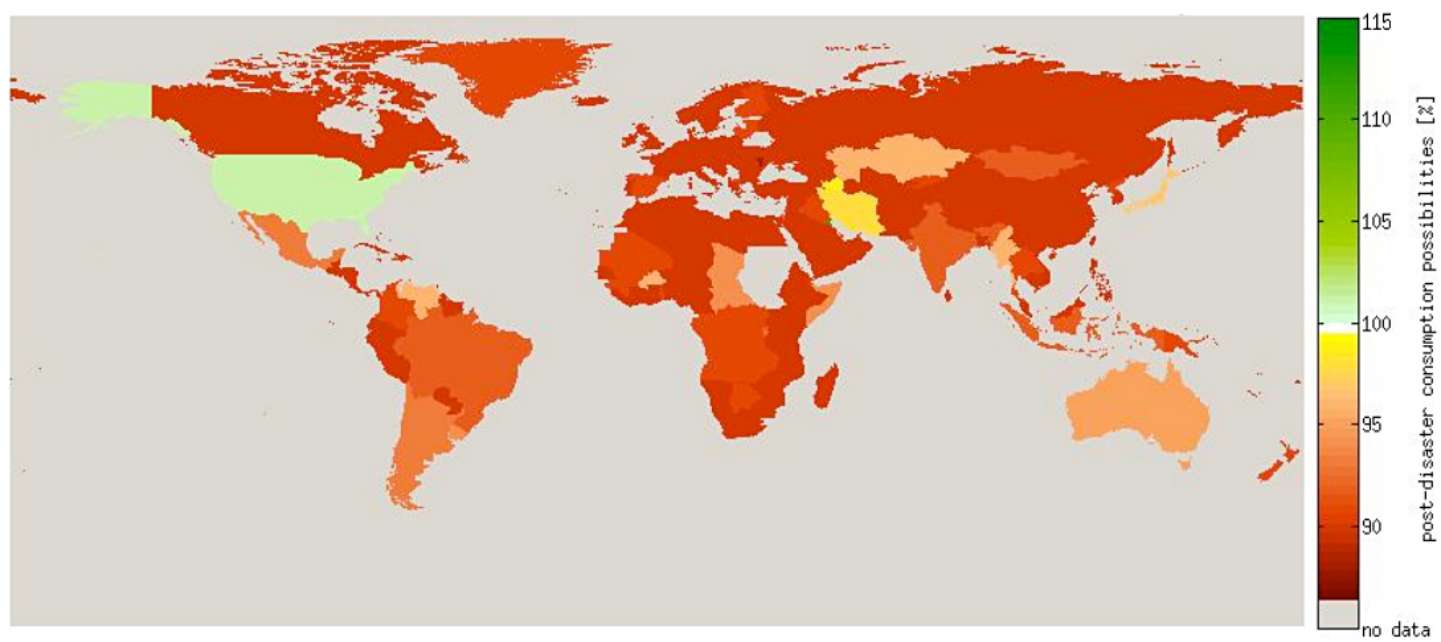

Figure 4. Storm scenario 2: a Quebec-like event centered over Europe. Due to Europe's participation in many global supply chains, a disaster in Europe would be felt not just in the continent itself, but in nearly all other countries in the world as well. The US is a notable exception: their economy could experience a slight increase in consumption possibilities in the post-disaster economy.

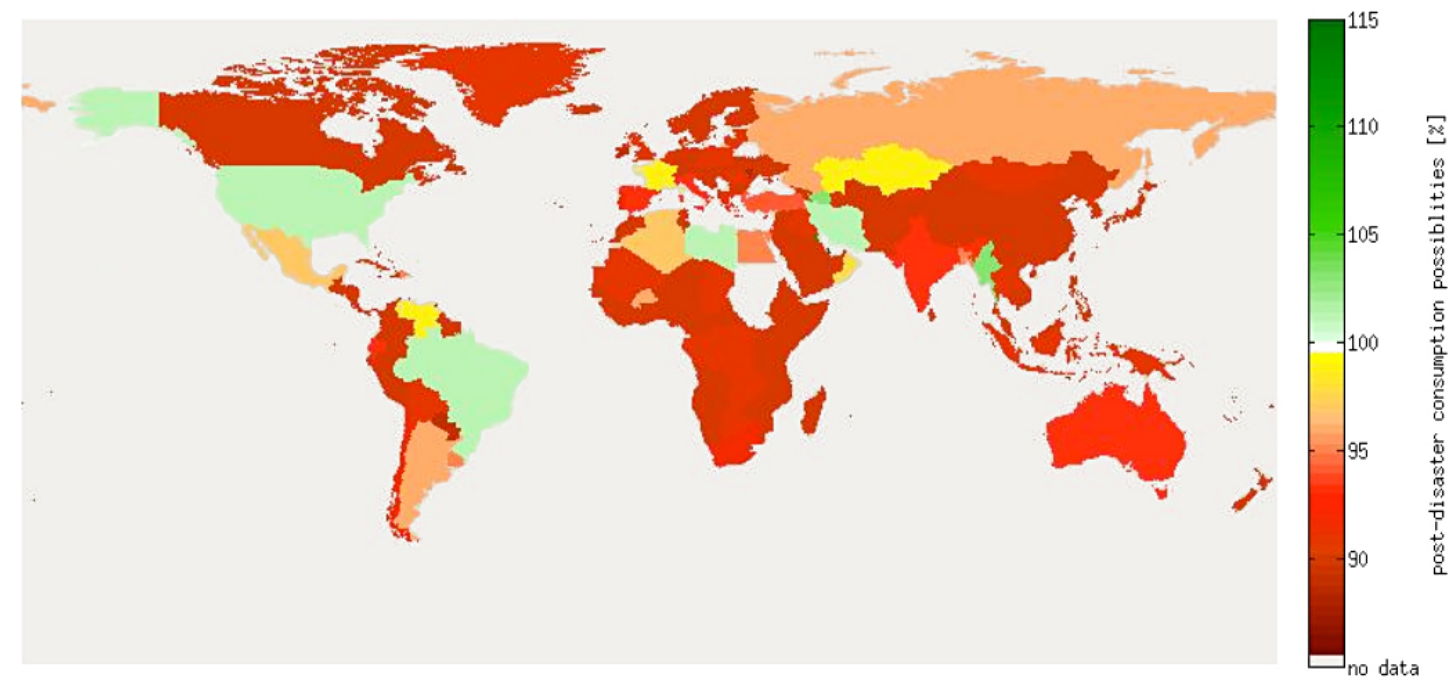

Figure 5. In scenario 3, an Australasian storm, the effects, again, are seen most strongly in the directly impacted countries and their trade partners. 
natural disasters on Earth. Whilst hurricanes, earthquakes and tsunamis could cause direct human losses, a solar storm is likely to cause material damage only. Although radiation risks for astronauts and airline passengers on polar routes are described in the literature, no human losses as a consequence of a solar storm have been recorded, and they are therefore not considered in this work, for example, as a loss of labor.

A severe space-weather event could be the worst natural disaster in modern history with global costs estimated to be over $5 \%$ of world GDP and impacts reaching across every industry and every segment of society. Extreme space weather will impact severely on society's infrastructure - networks of trade, transport and production would need to adapt globally. In our modern, globalized economy, shocks to the production system in one country can cause large ripple effects in partner economies. Reduced inventories, increased shipping, the rise of just-in-time production and the acceleration of specialization and trade mean that the global economic production system, while more productive in total, is increasingly more vulnerable to shocks. We have considered the possible impact of a century-scale space-weather event on the global economy. The results indicate that total losses could be up to USD 3.4 trillion or $5.6 \%$ of global GDP, and impacts would affect sectors and populations well outside the direct area of impact. Changes in the intensity and timing of a spaceweather event result in different global economic damage.

In comparison, global financial-crisis episodes lead to losses estimated between 2.95 and $4.54 \%$ of world GDP (Kappy and Vegaz, 2012). Economic impacts from climate change have been estimated to cost USD 125 billion $\mathrm{yr}^{-1}$ (GHF, 2009). Our scenario estimates global GDP damage in between climate change and global financial crisis.

\section{Conclusions}

For the first time, a physical and economic model have been combined to analyze the global economic impacts of severe space-weather events affecting major global industrial regions like the Northeastern USA, central Europe, and Southeast Asia. Macroeconomic models, such as the input-output model we are using in this study, have been used for impact analysis for some time. Such models can be used specifically to provide an estimate of the system-wide impact, including those of international trade and global supply chains.

We find that a severe space-weather event could lead to global economic damage of the same order as wars, extreme financial crisis, and estimated future climate change. But some countries may even benefit from the disaster in terms of higher domestic-consumption possibilities. A lot of details of the dependencies between solar activity, geomagnetic activity, and failure of electric distribution systems are still unclear. However, we provided a new physical model that relates the damage done to the national power systems to the strength and size of a geomagnetic storm. 


\section{Appendix A: Disaster impact method}

Assume a disaster analysis setting as in Steenge and Bokarjova (2007). In its original form, this method allowed only for changes in consumption possibilities, i.e., reductions in final demand, and excess production available for final demand. There is no provision for situations in which the production loss is larger than total final demand, i.e., where intermediate demand has to be affected by the disaster. In this study, this circumstance is dealt with by introducing sharing parameters, and dividing the total damage to a sector between its deliveries to intermediate and to final demand. This way, a situation in which damage to final demand is larger than that of total final demand can always be avoided by setting the share parameter appropriately.

Reductions in the production of a damaged sector only affect those intermediate sectors that receive a significant enough input from the damaged sector. Intermediate sectors that receive only marginal inputs from a damaged sector are assumed to be able to substitute for the reduced input, or slightly alter their production recipe otherwise, so they can keep producing at pre-disaster levels. The distinction between marginal and significant inputs is controlled by manually setting a threshold.

Let $\mathbf{A}$ be an $N \times N$ input-coefficient matrix, $\boldsymbol{y}(N \times 1)$ final demand, $\boldsymbol{x}(N \times 1)$ total output, and $\mathbf{I}$ a suitable identity matrix. Define $\{\tilde{\boldsymbol{x}}, \tilde{\boldsymbol{y}}\}$ as the post-disaster quantities of $\{\boldsymbol{x}, \boldsymbol{y}\}$. As in Steenge et al. (2007), we ask that the post-disaster economy $\{\tilde{\boldsymbol{x}}, \tilde{\boldsymbol{y}}\}$ is in balance:

$\tilde{\boldsymbol{x}}=\mathbf{A} \tilde{\boldsymbol{x}}+\tilde{\boldsymbol{y}} \Leftrightarrow(\mathbf{I}-\mathbf{A}) \tilde{\boldsymbol{x}}-\tilde{\boldsymbol{y}}=0 \Leftrightarrow[\mathbf{I}-\mathbf{A}-\mathbf{I}]\left[\frac{\tilde{\boldsymbol{x}}}{\tilde{\tilde{y}}}\right]=0$.

Introduce damage parameters $\Gamma$ so that $\tilde{x}_{i}=\left(1-\Gamma_{i}\right) x_{i} . \Gamma_{i}$ is the relative production loss of sector $i .1-\Gamma_{i}$ is the relative remaining capacity of sector $i$. The following approach let part of the production loss affect intermediate demand, so that the loss affecting final demand is never larger than total final demand itself: $y_{i}-\tilde{y}_{i}=\lambda_{i}\left(x_{i}-\tilde{x}_{i}\right)=\lambda_{i} \Gamma_{i} x_{i} \Leftrightarrow \tilde{y}_{i}=$ $y_{i}-\lambda_{i} \Gamma_{i} x_{i} \cdot \lambda_{i}$ is the factor that splits the production loss $x_{i}-\tilde{x}_{i}$ into a fraction $y_{i}-\tilde{y}_{i}$ imposed on final demand, and the remainder on intermediate demand. Assuming a constant production recipe $\mathbf{A}=$ const., a reduction in only one intermediate input $T_{\mathrm{ij}}$ from a damaged sector $i$ means that the entire production of sector $j$ must go down in the same proportion as the reduced input $i$. Here, the production of those sectors $j$ is reduced, where input $i$ formed a significant contribution of sector $j$ 's production recipe. Where this is not the case, sectors $j$ are allowed to operate at pre-disaster levels of output.
The loss of production of the electricity sector(s) is represented by $\Delta x_{\mathrm{el}}=\gamma_{\mathrm{el}} \cdot x_{\mathrm{el}}$. This loss affects the power supply to households and to other industrial, non-electricity sectors, and is distributed according to $D_{\mathrm{el}}=y_{\mathrm{el}} / x_{\mathrm{el}}=\Delta y_{\mathrm{el}} / \Delta x_{\mathrm{el}}$. We assume the fraction of production capacity lost in nonelectricity sectors to be $\gamma_{i \neq e l}=\Delta y_{\mathrm{el}} / y_{\mathrm{el}}=\Delta T_{\mathrm{el}} / T_{\mathrm{el}}$. We generally find

$$
\frac{\Delta T}{T}=\frac{\Delta x-\Delta y}{x-y}=\frac{\frac{\Delta y}{D}-\Delta y}{y / D-y}=\frac{\Delta y\left(\frac{1}{D}-1\right)}{y\left(\frac{1}{D}-1\right)}=\frac{\Delta y}{y} .
$$

Thereafter, final and intermediate demand is relative (not necessarily absolute) curtailed equally. If $\Delta x=\Delta y$, i.e., $\Delta T=0$, one would minimize total economic damage, because the indirect impacts on supply chains and international trade are missing from the assessment of the damage caused by the geomagnetic storm. 
Acknowledgements. Author contributions: H. Schulte in den Bäumen, D. Moran, M. Lenzen, and A. Steenge designed research, H. Schulte in den Bäumen and M. Lenzen performed research and analyzed data; H. Schulte in den Bäumen, M. Lenzen and I. Cairns wrote the paper. Competing financial interests: the author(s) declare no competing financial interests.

Edited by: R. Lasaponara

Reviewed by: M. A. Hapgood and one anonymous referee

\section{References}

Baumjohann, W., Untiedt, J., and Greenwald, R. A.: Joint twodimensional observations of ground magnetic and ionospheric electric fields associated with auroral zone currents: 1 . Threedimensional current flows associated with a substorm-intensified eastward electrojet, J. Geophys. Res., 85, 1963-1978, 1980.

Bolduc, L.: GIC observations and studies in the Hydro-Québec power system, J. Atmos. Sol.-Terr. Phy., 64, 1793-1802, 2002.

Boteler, D. H., Pirjola, R. J., and Nevanlinna, H.: The effects of geomagnetic disturbances on electrical systems at the Earth's surface, Adv. Space Res., 22, 17-27, 1998.

Cliver, E. W. and Svalgaard, L.: The 1859 solar-terrestrial disturbance and the current limits of extreme space weather activity, Sol. Phys., 224, 407-422, 2004.

Erinmez, I. A.: Management of the geomagnetically induced current risks on the national grid company's electric power transmission systems, J. Atmos. Sol.-Terr. Phy., 64, 743-756, 2002.

GHF: The human impact report on climate change: The anatomy of a silent crisis, Geneva, available at: http://www.ghf-ge.org/ human-impact-report.pdf (last access: 4 June 2014), 2009.

Green, J., Boardsen, S., and Odenwald, S.: Eyewitness accounts of the 1859 superstorm, Adv. Space Res., 38, 145-154, 2006.

Hapgood, M.: Prepare for the coming space weather storm, Nature, 484, 311-313, doi:10.1038/484311a, 2012.

Kappenman, J.: Geomagnetic Storms and their Impacts on the U.S. Power Grid, Metatech Corporation, 358 S. Fairview Ave., Suite E, Goleta, CA 93117, available at: www.ornl.gov/sci/ees/etsd/ pes/pubs/ferc_Meta-R-319.pdf (last access: 4 June 2014), 2010.

Kappy, D. and Vegaz, M.: Real Output Costs of Financial Crises: A Loss Distribution Approach, available at: http://mpra.ub. uni-muenchen.de/38988/ (last access: 4 June 2014), 2012.

Lakhina, G. S., Alex, S., Tsurutani, B. T., and Gonzalez, W. D.: Research on historical records of geomagnetic storms, Coronal and Stellar Mass Ejections, IAU Symposium Proceedings of the International Astronomical Union 226, Held 13-17 September, Beijing, edited by: Dere, K., Wang, J., and Yan, Y., Cambridge: Cambridge University Press, 3-15, 2005

Lenzen, M., Moran, D., Kanemoto, K., Foran, B., Lobefaro, L., and Geschke, A.: International trade drives biodiversity threats in developing nations, Nature, 486, 109-112, 2011.

Lenzen, M., Kanemoto, K., Moran, D., and Geschke, A.: Mapping the structure of the world economy, Environ. Sci. Technol., 46, 8374-8381, 2012.

Lenzen, M., Moran, D., Kanemoto, K., and Geschke, A.: Building Eora: a global multi-region input-output database at high country and sector resolution, Econom. Syst. Res., 25, 20-49, 2013.
Leontief, W.: Input-Output Economics, Oxford University Press, New York, NY, USA, 1966.

Leontief, W. and Strout, A.: Multi-Regional Input-Output. Analysis, in: Structural Interdependence and Economic. Development, edited by: Barna, T., Macmillan, London, UK, 119-149, 1963.

Li, J., Crawford-Brown, F., Syddall, M., and Guan, D.: Modeling imbalanced economic recovery following a natural disaster using input-output analysis, Risk Anal., 33, 1908-1923, 2013.

Lloyd's: Solar Storm risk to the North American grid, available at: www.lloyds.com (last access: 4 June 2014), 2013.

Love, J. J.: Credible occurrence probabilities for extreme geophysical events: earthquakes, volcanic eruptions, magnetic storms, Geophys. Res. Lett., 39, L10301, doi:10.1029/2012GL051431, 2012.

MITRE Corporation: JASON Report, "Impacts of Severe Space Weather on the Electric Grid", The MITRE Corporation JASON Program Office, 7515 Colshire Drive McLean, Virginia 22102, USA, 2011.

NAOS: US National Academy of Sciences, Severe Space weather Events - Understanding Societal and Economic Impacts, a workshop report, Washington, DC: The National Academies Press, 2008.

OECD: Office of Risk Management and Analysis: "Geomagnetic Storms", available at: www.oecd.org/dataoecd/57/25/46891645. pdf (last access: 4 June 2014), 2011.

OECD/IFP Futures Project on Future Global Shocks, US Department of Homeland Security, Office of Energy Delivery \& Electric Reliability: "Large Power Transformers and the U.S. Electric Grid", Report, available at: http://energy.gov/oe/downloads/ large-power-transformers-and-us-electric-grid-report-june-2012, 2012.

Okuyama, Y.: Economic modeling for disaster impact analysis: past, present, and future, Econom. Syst. Res., 19, 115-124, 2007.

Pirjola, R. J., Viljanen, A., Pulkkinen, A., and Amm, O.: Space weather risk in power systems and pipelines, Phys. Chem. Earth Pt. C, 25, 333-337, 2000.

Riley, P.: On the probability of occurrence of extreme space weather events, Pete Riley, Space Weather, 10, S02012, doi:10.1029/2011SW000734, 2012.

Royal Academy of Engineering: Extreme space weather: impacts on engineered systems and infrastructure, London, available at: http://www.raeng.org.uk/spaceweather (last access: 9 September 2014), 2013.

Siscoe, G., Crooker, N. U., and Clauer, C. R.: Dst of the Carrington storm of 1859, Adv. Space Res., 38, 173-179, 2006.

Showstack, R.: Threat of severe space weather to the U.S. electrical grid explored at conference, EOS T. Am. Geophys. Un., 92, 374375, 2011.

Steenge, A. E. and Boèkarjova, M.: Thinking about imbalances in post-catastrophe economies: an input-output based proposition, Econom. Syst. Res., 19, 205-217, 2007.

Thomson, A. W. P., Dawson, E. B., and Reay, S. J.: Quantifying extreme behavior in geomagnetic activity, Space Weather, 9, S10001, doi:10.1029/2011SW000696, 2011.

Tsurutani, B. T., Gonzalez, W. D., Lakhina, G. S., and Alex, S.: The extreme magnetic storm of 1-2 September 1859, J. Geophysics. Res., 108, 1268, doi:10.1029/2002JA009504, 2003. 
Tsurutani, B. T., Verkhoglyadova, O. P., Mannucci, A. J., Lakhina, G. S., and Huba, L. D.: Extreme changes in the dayside ionosphere during a Carrington-type magnetic storm, Space Weather Space Clim., 5, A05, doi:10.1051/swsc/2012004, 2012.

Tukker, A. and Dietzenbacher, E.: Global multiregional inputoutput frameworks: an introduction and outlook, Econom. Syst. Res., 25, 1-19, 2013.

UK House of Commons Defence Committee, Developing Threats: Electro-Magnetic Pulses (EMP), JASON Report, available at: http://go.nature.com/edi8qf (last access: 4 June 2014), 2012.
UNSD: National Accounts Main Aggregates Database, New York, USA, United Nations Statistics Division, available at: http:// unstats.un.org/unsd/snaama/Introduction.asp (last access: 4 June 2014), 2011.

Wei, L. H., Homeier, N., and Gannon, J. L.: Surface electric fields for North America during historical geomagnetic storms, Adv. Space Res., 11, 451-462, 2013.

Wiedmann, T. O., Schandl, H., Lenzen, M., Moran, D., Suh, S., West, J., and Kanemoto, K.: The material footprint of nations, P. Natl. Acad. Sci. USA, doi:10.1073/pnas.1220362110, 2013. 